14. Магомедов, Р.М. История Дагестана с древнейших времен до начала XIX в. / Р.М. Магомедов. - Махачкала: Дагучпедиздат, 1991. - 302 с.

15. Артемов, А.В. Производство изделий из кожи проблемы экологии / А.В. Артемов // Экология и промышленность России. - февраль. - 2004. - С.32-35.

16. Гаджимурадов, С.М. Основы ковроделия / С.М. Гаджимурадов. - Махачкала: Дагучпедиздат, 1993. - 130 с.

17. Дебиров, П.М. Ковры Дагестана: традиционное и современное / П.М. Дебиров. Махачкала: ДГПУ, 1995. - 94 с.

18. Walters, A., An overview of textiles processing and related environmental concerns [Электронный pecypc] / A. Walters, D. Santillo, P. Johnston // Greenpeace research laboratories: Department of biological sciences. - 2005. - June. - Режим доступа: www.greenpeace.to/publications/textiles 2005.

19. Артемов, А.В. Производство изделий из кожи проблемы экологии / А.В. Артемов // Экология и промышленность России. - февраль. - 2004. - С.32-35.

20. Савостицкий, Н.А. Материаловедение швейного производства / Н.А. Савостицкий, Э.К. Амирова. - М.: Академия, 2000. - 240 с.

21. Федеральный закон РФ «Об охране окружающей среды» № 7-Ф3 от 10.01.2002 г.

УДК 664.8.036.62

Ахмедов М.Э., Демирова А.Ф., Загиров Н.Г., Пиняскин В.В., Ахмедова М.М.

ОБОСНОВАНИЕ ОПТИМАЛЬНЫХ ПАРАМЕТРОВ И МАТЕМАТИЧЕСКАЯ МОДЕЛЬ ВЫСОКОТЕМПЕРАТУРНОЙ РОТАЦИОННОЙ СТЕРИЛИЗАЦИИ КОМПОТОВ В ТАРЕ СКО-1-82-3000

Achmedov M.E., Demirova A.F., Zagirov N.G., Pinyaskin V.V., Achmedova M.M.

\title{
JUSTIFICATION OF OPTIMUM PARAMETERS AND MATHEMATICAL MODEL OF HIGH-TEMPERATURE ROTATIONAL STERILIZATION OF COMPOTES IN SKO-1- 82-3000 CONTAINER
}

Проведень исследования для выяснения влияния температуры и скорости нагретого воздуха на динамику и продолжстельность прочесса нагрева компотов в таре СКО 1-82-3000. Исследования проведены при скоростях нагретого воздуха от 1,2 м/с до $8,5 \mathrm{M} / \mathrm{c}$ u meмnературах $120-150^{\circ} \mathrm{C}$.

Выявлено, что для банки СКО 1-82-3000 оптимальной температурой теплоносителя (нагретого воздуха) можно считать $t_{6}=150$ u выше ${ }^{0} C$. Анализ экспериментальных данных и их обработка с использованием метода наименьших квадратов позволили получить уравнение для расчета продолжительности нагрева компотов в потоке нагретого воздуха в таре СКО 1-82-3000 в зависимости от температуры греющей среды $t_{6}$ и ее скорости $v_{6}$.

Относительная погрешность при сопоставлении расчетных и опытных данных колеблется в пределах 5-8\%.

Ключевые слова: компот, стерилизачия, температура, скорость, продолжительность нагрева, воздушный поток, теплоноситель, уравнение.

Researches for clarification of influence of temperature and speed of heated air on dynamics and duration of process of heating of compotes in SKO 1-82-3000 container are conducted. Researches are conducted at speeds of heated air from $1,2 \mathrm{~m} / \mathrm{s}$ to $8,5 \mathrm{~m} / \mathrm{s}$ and temperatures $120-150^{\circ} \mathrm{C}$. 
It is revealed that for SKO 1-82-3000 banks it is possible to consider as the optimum temperature of the heat carrier (heated air) $t_{v}=150$ and higher than ${ }^{0} C$. The analysis of experimental data and their processing with use of a method of the smallest squares allowed to receive the equation for calculation of duration of heating of compotes in a stream of heated air in SKO 1-82-3000 container depending on temperature of the heating $t_{v}$ environment and its speed $v_{6}$.

The relative error by comparison of settlement and skilled data fluctuates within 5-8\%

Key words: compote, sterilization, temperature, speed, heating duration, air stream, heat carrier, equation.

Основной задачей стерилизации консервов является уничтожение или инактивация микроорганизмов, способных вызвать опасную для здоровья потребителей порчу пищевых продуктов. При этом необходимо помнить и об обратной стороне этого вопроса: необходимости как можно более полного сохранения всех качественных показателей продукта [1,2].

Для обеспечения проведения процесса стерилизации, удовлетворяющего обоим этим требованиям, необходим научно обоснованный выбор основных параметров процесса стерилизации, основу которого составляют термоустойчивость микроорганизмов, химическая и физическая природа пищевых продуктов и скорость проникновения тепла в банку с продуктом.

Как известно из литературных источников[1], уничтожение микроорганизмов можно осуществить при разных температурах, начиная приблизительно с $60-70^{\circ} \mathrm{C}$, выдерживая в течение определенного времени, носящего название “смертельного времени”, и поэтому какой-то определенной температуры, смертельной для данного вида микроорганизмов, не существует. Так, вегетативные клетки бактерий, дрожжей и плесени погибают почти мгновенно при температуре $100^{\circ} \mathrm{C}$, в то время как споры определенных бактерий исключительно устойчивы к нагреванию и для их уничтожения необходима продолжительная выдержка при высоких температурах. Скорость протекания процесса отмирания микроорганизмов является функцией времени и температуры, которые взаимно изменяются при прочих равных условиях, и чем выше температура, воздействующая на клетки, тем скорее они погибают. Поэтому летальные условия не могуг быть выражены только одной температурой, а только в совокупности со временем выдержки при данной температуре [1]. При этом зависимость между смертельным временем и температурой является обратной, т.е. с повышением температуры стерилизации смертельное время снижается, причем относительно небольшое увеличение температуры стерилизации значительно влияет на продолжительность смертельного времени, или, если температуру стерилизации повышать в арифметической прогрессии, то смертельное время уменьшается в геометрической прогрессии.

Достижение полной стерильности консервов, т.е. полное уничтожение всех микроорганизмов, в промышленных условиях практически невозможно и не нужно: в продукте даже после очень жестких режимов стерилизации могут выжить единичные клетки микроорганизмов, которые, тем не менее, никак не являются признаком микробиологического неблагополучия консервов, поскольку они, хотя и остаются жизнеспособными, но сильно ослаблены и при нормальных условиях хранения не растут. Только при хранении в экстремальных условиях, особенно благоприятных для их роста, они могут размножаться.

Учитывая логарифмический характер гибели микроорганизмов при нагревании, полностью уничтожить их при стерилизации невозможно.

И промышленная стерилизация не ставит своей задачей обеспечение абсолютной стерильности продукта, так как абсолютная стерильность может быть достигнута нагревом и длительной выдержкой банок с продуктом при весьма высоких температурах, 
при которых продукт претерпевает настолько глубокие изменения, что становится непригодным к употреблению.

Поэтому при выборе режимов стерилизации консервов следует исходить из того, что режим стерилизации должен обеспечивать заданную промышленную стерильность консервов, но не более. Чем выше биологическая ценность исходного сырья, тем больше его потери при тепловом воздействии, поэтому при обработке такого продукта следует предъявлять более высокие требования к технологии [2,3,4] и, в частности, к выбору режима тепловой стерилизации.

Современный подход к решению вопросов стерилизации консервов заключается в изыскании таких способов и режимов стерилизации, которые обеспечивали бы, наряду с необходимой инактивацией микрофлоры, и более полное сохранение пищевой ценности готового продукта.

Как было сказано выше, основным фактором, который играет существенную роль в процессе тепловой стерилизации пищевых продуктов, является температура продукта. Динамика изменения температуры в наименее прогреваемой точке и продолжительность самого процесса нагрева продукта до заданной конечной температуры являются основополагающими факторами для исследования, расчета и разработки режимов тепловой стерилизации консервов [5,6,7]. При этом при тепловой обработке пищевых продуктов с вращением тары при оптимальных параметрах вращения, обеспечивающих практически равномерную тепловую обработке по всему объему банки, понятие «наименее прогреваемая точка» практически уже не играет той роли, которая имеет место при стерилизации консервов в статическом состоянии банок.

Вместе с тем, существенную роль в интенсификации внешнего теплообмена при стерилизации консервов в потоке нагретого воздуха играет не только температура теплоносителя (нагретого воздуха), но и его скорость [4], которая также существенно способствует интенсификации процесса внешнего теплообмена.

Для определения влияния температуры и скорости нагретого воздуха на динамику и продолжительность процесса нагрева компотов, нами проведены экспериментальные исследования прогреваемости компотов в стеклянной таре СКО 1-82-3000. Исследования проведены при следующих параметрах теплоносителя: скорость 1,2 м/с - 8,5м/с; температура $120-150^{\circ} \mathrm{C}$.

На рис. 1 представлены кривые прогреваемости консервов «Компот из черешни» при вращении банки СКО 1-82-3000 с «донышка на крышку» с $\mathrm{n}=0,33 \mathrm{c}^{-1}$ (оптимальная частота вращения для банки СКО 1-82-3000) в потоке нагретого воздуха температурой $120^{\circ} \mathrm{C}$ при различных скоростях воздушного потока: $1-v_{\mathrm{B}}=1,2 \mathrm{M} / \mathrm{c} ; 2-\mathrm{v}_{\mathrm{B}}=3,5 \mathrm{M} / \mathrm{c} ; 3-$ $v_{\mathrm{B}}=5,75 \mathrm{M} / \mathrm{c} ; 4-v_{\mathrm{B}}=6,5 \mathrm{M} / \mathrm{c} ; 5-v_{\mathrm{B}}=8,5 \mathrm{M} / \mathrm{c}$

Как видно из рис. 1 , продолжительность нагрева компота от $\mathrm{t}_{\mathrm{H}}=50^{\circ} \mathrm{C}$ до $\mathrm{t}_{\mathrm{K}}=100^{\circ} \mathrm{C}$ составляет при скорости воздушного потока, равной $v_{\mathrm{B}}=1,2 \mathrm{M} / \mathrm{c}-90$ мин. Увеличение скорости воздушного потока до $v_{\mathrm{B}}=3,5 \mathrm{~m} / \mathrm{c}$, при неизменной ее температуре, приводит к сокращению продолжительности процесса нагрева компота до $100^{\circ} \mathrm{C}$, которая составляет при этих параметрах - 69 мин. Дальнейшее увеличение скорости нагретого воздуха до $v_{\mathrm{B}}=5,75 \mathrm{~m} / \mathrm{c}$ также приводит к сокращению продолжительности процесса нагрева до 53 мин, и этот процесс сокращения продолжительности процесса нагрева компота, в зависимости от увеличения скорости нагретого воздуха, продолжается и дальше, но, однако, зависимость продолжительности нагрева от скорости теплоносителя постепенно становится несколько менее заметной. В частности, при увеличении скорости воздушного потока с $v_{\mathrm{B}}=5,75 \mathrm{~m} / \mathrm{c}$ до $v_{\mathrm{B}}=6,5 \mathrm{~m} / \mathrm{c}$, продолжительность процесса нагрева до заданной конечной температуры сокращается на 3 мин, т.е. составляет 50 мин, при скорости $v_{\mathrm{B}}=8,5$ м/с - составляет порядка 43 мин. 


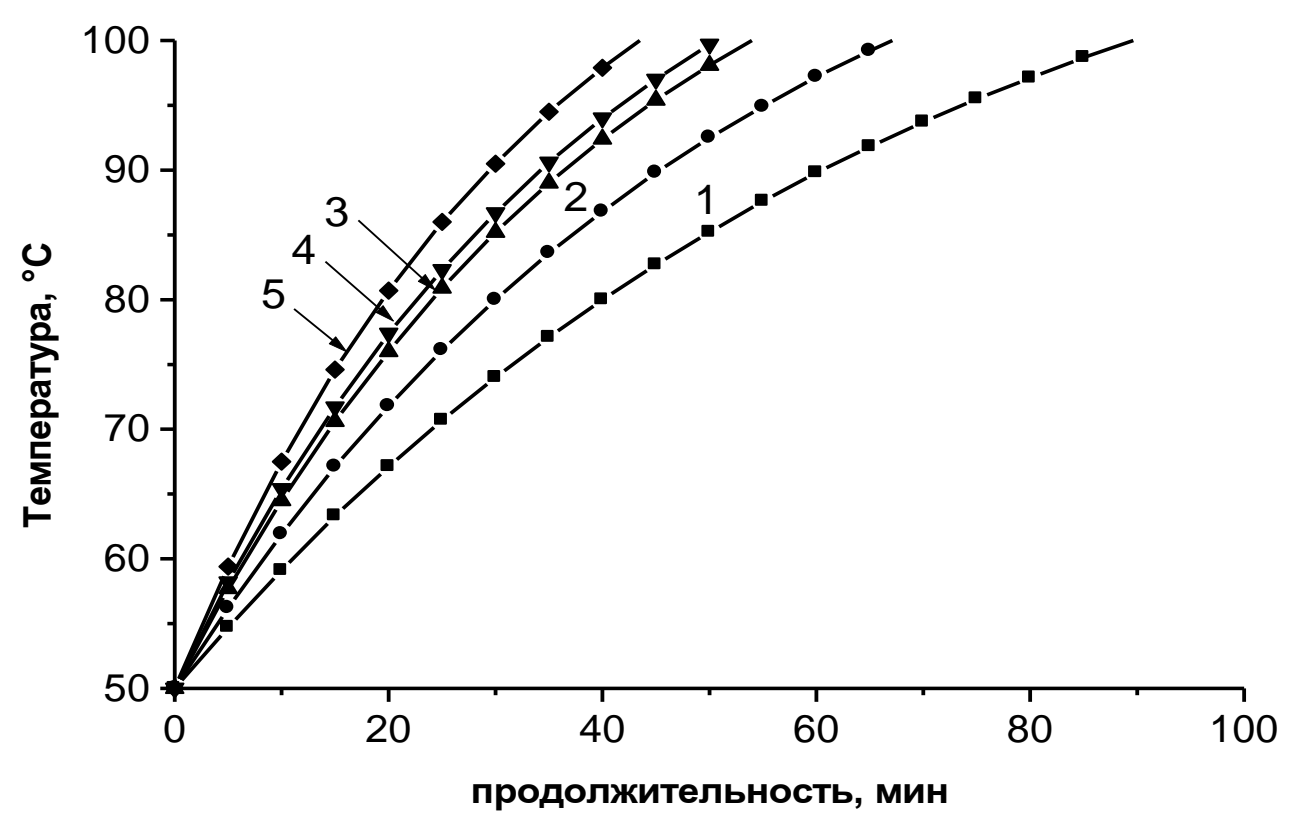

Рисунок 1 - Кривые прогреваемости наименее прогреваемой точки консервов «Компот из черешни» при вращении банки СКО 1-82-3000 с «донышка на крышку» с частотой $\mathrm{n}=0,33 \mathrm{c}^{-1}$ при температуре нагретого воздуха $\mathrm{t}_{\mathrm{B}}=120^{\circ} \mathrm{C}$ и различных скоростях воздушного потока: 1) $v_{\mathrm{B}}=1,2 \mathrm{M} / \mathrm{c}$; 2) $\left.\left.\left.v_{\mathrm{B}}=3,5 \mathrm{M} / \mathrm{c} ; 3\right) v_{\mathrm{B}}=5,75 \mathrm{M} / \mathrm{c} ; 4\right) v_{\mathrm{B}}=6,5 \mathrm{M} / \mathrm{c} ; 5\right) v_{\mathrm{B}}=8,5 \mathrm{M} / \mathrm{c}$

Таким образом, анализ кривых прогреваемости консервов «Компот из черешни» в банках СКО 1-82-3000 с вращением тары в потоке нагретого воздуха температурой $120^{\circ} \mathrm{C}$ показывает, что скорость воздушного потока в пределах $v_{\mathrm{B}}=8-8,5 \mathrm{~m} / \mathrm{c}$ можно считать оптимальной, так как дальнейшее увеличение скорости воздушного потока практически мало влияет на сокращение продолжительности процесса нагрева.

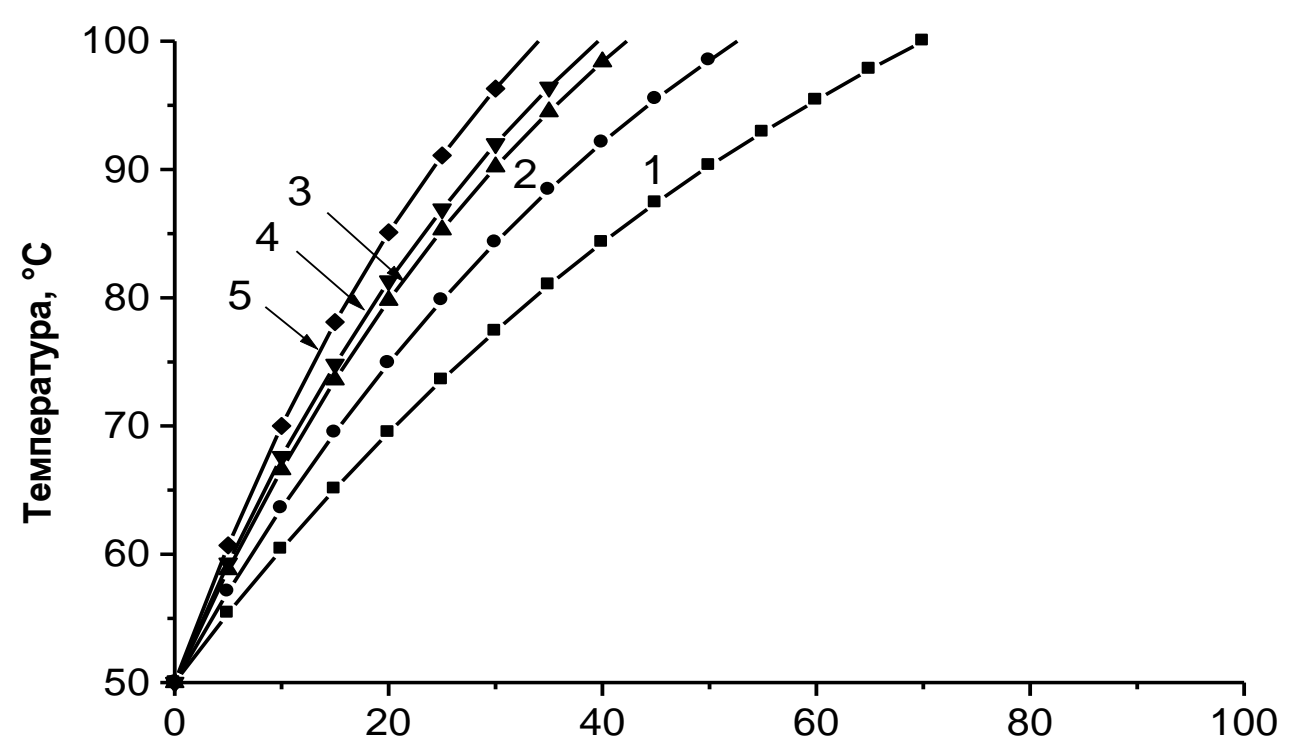

Рисунок 2 - Кривые прогреваемости наименее прогреваемой точки консервов «Компот из черешни» при вращении банки 1-82-3000 с «донышка на крышку» с частотой $\mathrm{n}=0,33 \mathrm{c}^{-1}$ при температуре нагретого воздуха $t_{\mathrm{B}}=130^{\circ} \mathrm{C}$ и различных скоростях воздушного потока: 1) $v_{\mathrm{B}}=1,2 \mathrm{M} / \mathrm{c}$; 2) $v_{\mathrm{B}}=3,5 \mathrm{M} / \mathrm{c}$; 3) $v_{\mathrm{B}}=5,75 \mathrm{M} / \mathrm{c}$; 4) $v_{\mathrm{B}}=6,5 \mathrm{M} / \mathrm{c}$; 5) $v_{\mathrm{B}}=8,5 \mathrm{M} / \mathrm{c}$ 
На рис. 2 представлены кривые прогреваемости консервов «Компот из черешни» при вращении банки СКО 1-82-3000 с «донышка на крышку» с частотой $\mathrm{n}=0,33 \mathrm{c}^{-1}$ при температуре нагретого воздуха $\mathrm{t}_{\mathrm{B}}=130^{\circ} \mathrm{C}$ и различных скоростях воздушного потока: 1 $v_{\mathrm{B}}=8,5 \mathrm{M} / \mathrm{c} ; 2-v_{\mathrm{B}}=6,5 \mathrm{M} / \mathrm{c} ; 3-\mathrm{v}_{\mathrm{B}}=4,75 \mathrm{M} / \mathrm{c} ; 4-v_{\mathrm{B}}=3,5 \mathrm{M} / \mathrm{c} ; 5-v_{\mathrm{B}}=1,5 \mathrm{M} / \mathrm{c} ; 6-v_{\mathrm{B}}=1,2 \mathrm{M} / \mathrm{c}$.

продолжительность, мин

Как видно из рис. 2, при минимальной скорости воздушного потока, равной $v_{\mathrm{B}}=1,2$ $\mathrm{M} / \mathrm{c}$, продолжительность процесса нагрева компота от $\mathrm{t}_{\mathrm{H}}=50^{\circ} \mathrm{C}$ до $\mathrm{t}_{\mathrm{K}}=100^{\circ} \mathrm{C}$ составляет -69 мин, т.е. на 21 мин меньше, чем при такой же скорости воздушного потока, но при температуре нагретого воздуха, равной $120^{\circ} \mathrm{C}$ (рисунок 1). Увеличение скорости воздушного потока приводит, соответственно, к сокращению продолжительности процесса нагрева, которая составляет при скорости $v_{\mathrm{B}}=3,5 \mathrm{~m} / \mathrm{c}-52$ мин и, уменьшаясь, в дальнейшем достигает при $v_{B}=8,5 \mathrm{~m} / \mathrm{c}$ величины, равной 32 мин. И при данной температуре также видно, что увеличение скорости воздушного потока выше 8-8,5 м/с менее существенно влияет на продолжительность процесса нагрева компотов.

На рис. 3 представлены кривые прогреваемости консервов «Компот из черешни» в банке СКО 1-82-3000 при нагреве в потоке нагретого воздуха температурой $140^{\circ} \mathrm{C}$ при различных скоростях теплоносителя и вращения тары с «донышка на крышку» с частотой $\mathrm{n}=0,133 \mathrm{c}^{-1}$. Как видно из рис. 3 , увеличение скорости воздушного потока с $v_{\mathrm{B}}=1,2 \mathrm{~m} / \mathrm{c}$ до $v_{\mathrm{B}}=8,5 \mathrm{~m} / \mathrm{c}$ приводит к сокращению продолжительности процесса нагрева компота с 58 мин (при $v_{\mathrm{B}}=1,2 \mathrm{M} / \mathrm{c}$ ) до 28 мин (при $v_{\mathrm{B}}=8,5 \mathrm{M} / \mathrm{c}$ ); т.е. увеличение скорости воздушного потока с $1,2 \mathrm{~m} / \mathrm{c}$ до 8,5 м/с обеспечивает сокращение продолжительности процесса нагрева на 20 мин и при этом так же, как и в предыдущем случае, оптимальной скоростью можно считать $v_{\mathrm{B}}=8 \div 8,5 \mathrm{M} / \mathrm{c}$.

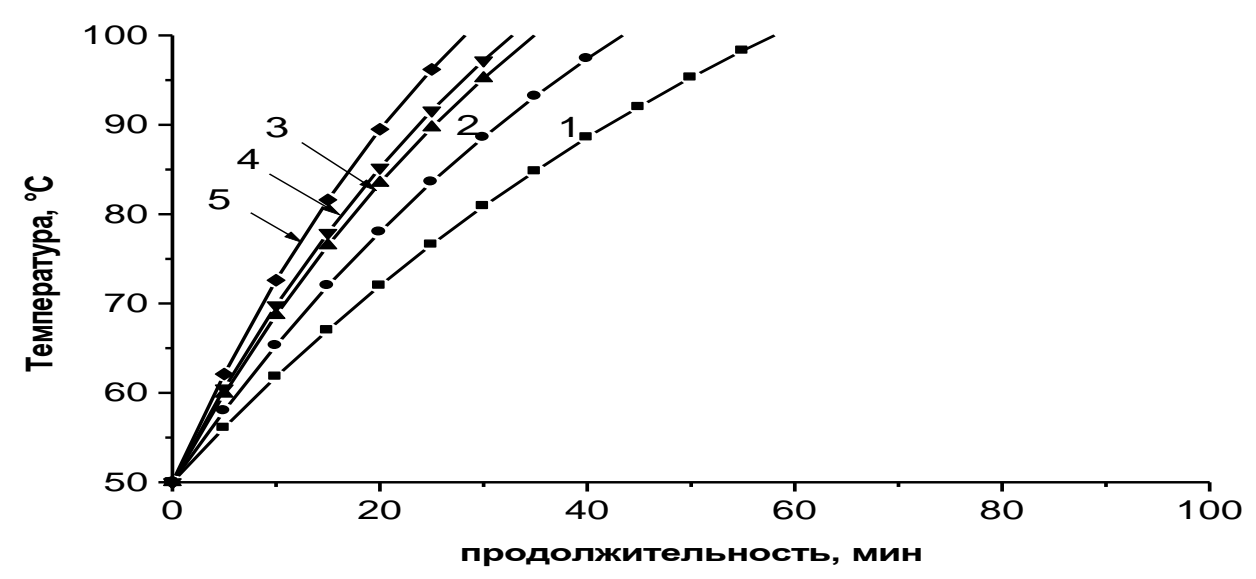

Рисунок 3 - Кривые прогреваемости наименее прогреваемой точки консервов «Компот из черешни» при вращении банки 1-82-3000 с «донышка на крышку» с частотой $\mathrm{n}=0,33 \mathrm{c}^{-1}$ при температуре нагретого воздуха $\mathrm{t}_{\mathrm{B}}=140^{\circ} \mathrm{C}$ и различных скоростях воздушного потока: 1) $v_{\mathrm{B}}=1,2 \mathrm{M} / \mathrm{c}$; 2) $v_{\mathrm{B}}=3,5 \mathrm{M} / \mathrm{c}$; 3) $v_{\mathrm{B}}=5,75 \mathrm{M} / \mathrm{c}$; 4) $\left.v_{\mathrm{B}}=6,5 \mathrm{M} / \mathrm{c} ; 5\right) v_{\mathrm{B}}=8,5 \mathrm{M} / \mathrm{c}$

Дальнейшее увеличение температуры нагретого воздуха до $150^{\circ} \mathrm{C}$ (рисунок 4) обеспечивает интенсификацию процесса теплообмена и, следовательно, также приводит к сокращению продолжительности процесса нагрева с 50 мин (при $v_{\mathrm{B}}=1,2 \mathrm{~m} / \mathrm{c}$ ) до 22 мин (при $v_{\mathrm{B}}=8,5 \mathrm{M} / \mathrm{c}$ ).

Анализ кривых прогреваемости, представленных на рисунках $1-4$, показывает, что увеличение температуры нагретого воздуха не обеспечивает пропорциональное ее величине сокращение продолжительности нагрева компотов: в частности при повышении температуры нагретого воздуха со $120^{\circ} \mathrm{C}$ до $130^{\circ} \mathrm{C}$, при одной и той же его скорости, продолжительность процесса нагрева компота до $100^{\circ} \mathrm{C}$ сокращается с 38 мин (при $\left.120^{\circ} \mathrm{C}\right)$ до 32 мин (при $130^{\circ} \mathrm{C}$ ), т.е. продолжительность сокращается на 6 мин. При дальнейшем 
увеличении температуры нагретого воздуха до $140^{\circ} \mathrm{C}$ продолжительность процесса нагрева при скорости воздушного потока, равной $v_{\mathrm{B}}=1,2 \mathrm{~m} / \mathrm{c}$, составляет 25 мин; и при температуре воздуха, равной $150^{0}-23$ мин.

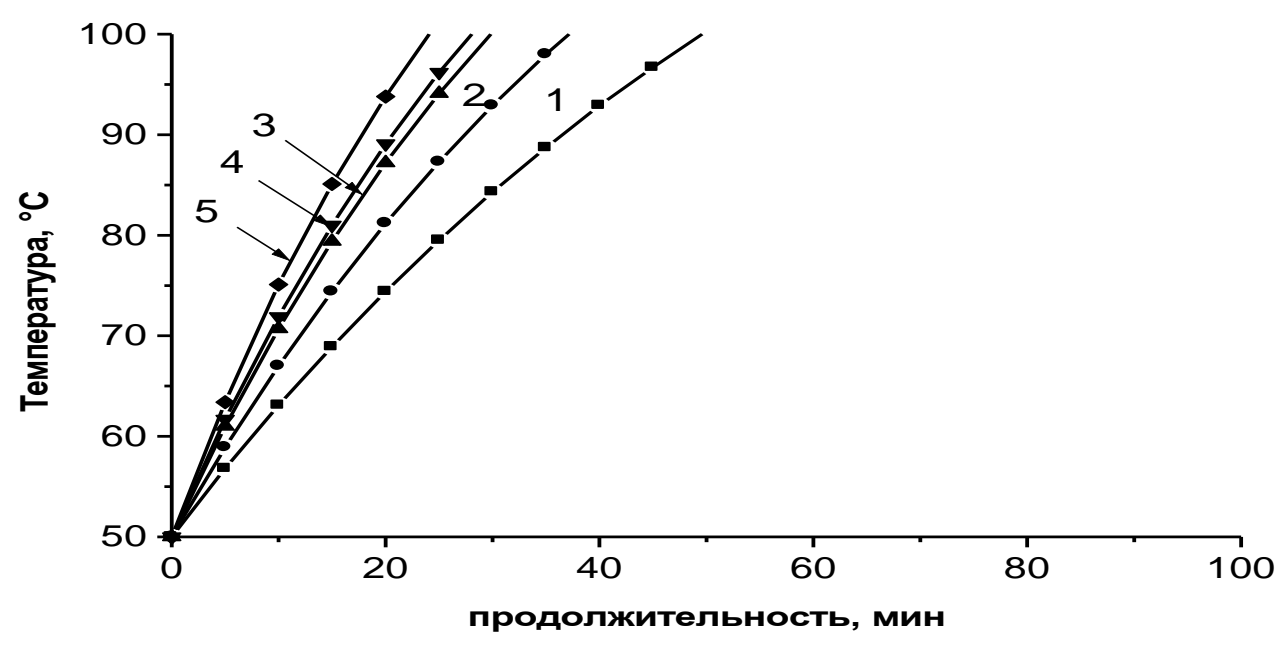

Рисунок 4 - Кривые прогреваемости наименее прогреваемой точки консервов «Компот из черешни» при вращении банки 1-82-3000 с «донышка на крышку» с частотой $\mathrm{n}=0,33 \mathrm{c}^{-1}$ при температуре нагретого воздуха $\mathrm{t}_{\mathrm{B}}=150^{\circ} \mathrm{C}$ и различных скоростях воздушного потока: 1) $\left.\left.\left.\left.v_{\mathrm{B}}=1,2 \mathrm{M} / \mathrm{c} ; 2\right) v_{\mathrm{B}}=3,5 \mathrm{M} / \mathrm{c} ; 3\right) v_{\mathrm{B}}=5,75 \mathrm{M} / \mathrm{c} ; 4\right) v_{\mathrm{B}}=6,5 \mathrm{M} / \mathrm{c} ; 5\right) v_{\mathrm{B}}=8,5 \mathrm{M} / \mathrm{c}$

Таким образом, можно сделать вывод о том, что для банки СКО 1-82-500 оптимальной температурой теплоносителя (нагретого воздуха) можно считать $\mathrm{t}_{\mathrm{B}}=140 \div 150^{\circ} \mathrm{C}$, и дальнейшее увеличение температуры нецелесообразно.

Анализ экспериментальных данных и их обработка с использованием метода наименыших квадратов позволили получить уравнение для расчета продолжительности нагрева компотов в потоке нагретого воздуха в таре СКО 1-82-3000 в зависимости от температуры греющей среды $t_{\text {в }}$ и ее скорости $v_{\text {в. }}$

Полученное уравнение при объеме тары СКО 1-82-3000, имеет вид:

$$
\tau=\frac{P_{1}-\sqrt{P_{2}-T}}{P_{3}},
$$

где $\mathrm{P}_{1}=2,9+0,038 \mathrm{t}_{\mathrm{B}} ; \mathrm{P}_{2}=33+0,6 \mathrm{t}_{\mathrm{B}} ; \mathrm{P}_{3}=0,084+0,0129 \mathrm{v}_{\mathrm{B}}$;

Относительная погрешность при сопоставлении расчетных и опытных данных колеблется в пределах 5-8\%.

Экспериментальные и расчетные значения по уравнению (1) представлены в таблице 1.

Таблица 1 - Зависимость продолжительность процесса нагрева компота от параметров теплоносителя

\begin{tabular}{|c|c|c|c|c|c|c|c|c|c|}
\hline \multirow{3}{*}{$\begin{array}{c}\text { Наименовани } \\
\text { е } \\
\text { тары }\end{array}$} & \multirow{3}{*}{$\begin{array}{c}\text { Скорость } \\
\text { нагретог } \\
\text { о } \\
\text { воздуха, } \\
\text { v }_{\text {в }} / \mathrm{c}\end{array}$} & \multicolumn{8}{|c|}{ Продолжительность нагрева от $t_{\mathrm{H}}=50^{\circ} \mathrm{C}$ до $\mathrm{t}_{\mathrm{k}}=100^{\circ} \mathrm{C}$, мин } \\
\hline & & \multicolumn{2}{|c|}{$120^{\circ} \mathrm{C}$} & \multicolumn{2}{|c|}{$130^{\circ} \mathrm{C}$} & \multicolumn{2}{|c|}{$140^{\circ} \mathrm{C}$} & \multicolumn{2}{|c|}{$150^{\circ} \mathrm{C}$} \\
\hline & & опыт. & расч. & пыт. & $\begin{array}{l}\quad p \\
\text { асч. }\end{array}$ & опыт. & расч. & опыт. & расч. \\
\hline \multirow{6}{*}{$\begin{array}{l}\text { СКО } \\
1-82-3000\end{array}$} & 1,2 & 88 & 90 & 68,5 & 70 & 57,5 & 58 & 48,5 & 50 \\
\hline & 2,75 & 73 & 74 & 55,8 & 57 & 48 & 47 & 41,0 & 41 \\
\hline & 4,75 & 57 & 59 & 44 & 46 & 38 & 38 & 33,5 & 33 \\
\hline & 6,5 & 52 & 51 & 39 & 40 & 33,5 & 33 & 29 , & 28 \\
\hline & 7,75 & 46 & 47 & 36,5 & 37 & 29,5 & 30 & 26 & 26 \\
\hline & 8,5 & 41,5 & 43 & 34,5 & 34 & 26 & 28 & 24 & 24 \\
\hline
\end{tabular}


Относительная погрешность при сопоставлении расчетных и опытных данных колеблется в пределах 5-8\%.

Анализ полученных экспериментальных данных показывает, что оптимальными параметрами для тепловой обработки компотов в таре СКО 1-82-3000 являются: температура 140 и $150^{\circ} \mathrm{C}$ и скорость воздушного потока $6,5-8,5 \mathrm{M} / \mathrm{c}$.

\section{Библиографический список:}

1. Флауменбаум Б.Л. Основы консервирования пищевых продуктов, -М. : Легкая и пищевая промышленность,1972.-260с.

2. Сборник технологических инструкций по производству консервов. Т-2, -М.: Легкая и пищевая промышленность, 1977.

3. Ахмедов М.Э.Интенсификация технологии тепловой стерилизации консервов «Компот из яблок» с предварительным подогревом плодов в ЭМП СВЧ //Известия вузов. Пищевая технология, 2008, № 1. - С. 15-16.

4. Ахмедов М.Э., Исмаилов Т.А. Прогреваемость консервов при стерилизации в потоке нагретого воздуха // Продукты длительного хранения, 2007, № 2. - С. 9-10.

5. Мурадов М.С. Изыскание высокотемпературных режимов ротационной стерилизации консервов в потоке воздуха: Дис...канд. техн. наук. - Одесса, 1978.

6. Ахмедов М.Э., Исмаилов Т.А. Математическое планирование эксперимента при ротационной стерилизации консервов в потоке нагретого воздуха //Хранение и переработка сельхозсырья, 2009, № 1. - С.

7. Ахмедов М.Э, Шихалиев С.С., Суракатов С.С., Рахманова М.М. Высокотемпературная ротационная стерилизация компотов //Пищевая промышленность, 2009, № 7. - C.30-31.

\section{УДК 547.789.9}

Абакаров Г.М.

\section{МЕТОДЫ СИНТЕЗА БЕНЗОСЕЛЕН(ТЕЛЛУР)АЗОЛОВ, 1,5 БЕНЗОТЕЛЛУРАЗЕПИНОВ И ИХ ПРОИЗВОДНЫХ}

Abakarov G. M.

\section{METHODS OF SYNTHESIS BENZOSELENIUM(TELLURIUM)AZOLES, 1,5- BENZOTELLURAZEPINES AND THEIR DERIVATIVES}

В данной статье рассмотрены методы получения бензоселен(теллур)азолов, 1,5бензотеллуразепинов и их производных.

Ключевые слова: селен, теллур, бис(аминофенил)дителлурид, 2-иодфенилизочианид, вторичные и ичиклические амины, дифениламин, морфолин.

In this article receiving methods benzoselenium(tellurium)azoles, 1,5-benzotellurazepines and their derivatives.

Key words: selenium, tellurium, bis(aminophenil)ditellurid, 2-iodfenilizotsianid, secondary and cyclic amines, diphenylamine, morfolin.

\section{1.Бензохалькогеназолы}

Химия халькогенорганических соединений является важным и интенсивно развивающим направлением элементорганической химии. Мощным стимулом для столь интенсивных исследований является разнообразие важных и полезных свойств этих 